Check for updates

Hurley Group, London

clare.gerada@nhs.net

Cite this as: BMJ 2020;370:m2860

http://dx.doi.org/10.1136/bmi.m2860

Published: 21 July 2020

WOUNDED HEALER

\title{
Clare Gerada: We must not rush back to business as usual
}

\section{Clare Gerada GP partner}

As we come to the end of the first phase of the covid pandemic it is good to review how this period has affected us, our patients, and our organisations. I have been doing this with respect to my service for doctors with mental illness, NHS Practitioner Health. After an initial dip in referrals, to around half the normal weekly numbers, we are now seeing more doctors presenting than at any time in our 12 year history.

These doctors are not randomly distributed across all specialties, levels of training, or seniority. Staff and associate grade and locum doctors have been more likely to present than consultants. General practitioners still top the list (albeit collectively they are the largest specialty group). They have had to deal rapidly with changes in teams and consulting styles, and many locum GPs have lost their livelihood.

Previously an under-represented group, surgeons are now second to GPs in numbers coming to the service. My reflection on this is that surgeons have had to stop their core work: operating. Even now they have limited access to theatre time because of current covid restrictions, and this is causing them great distress.

International medical graduates (IMGs), normally around $13 \%$ of referrals to NHS Practitioner Health, have increased in this phase to $25 \%$ and remain high. Those from ethnic minority groups have been disproportionately affected during this pandemic, and it should not be surprising that this translates into doctors from these communities also suffering more from mental illness during these difficult times. Not only are they more likely to be in locum and unstable peripatetic posts but they have had to face the increased burden of risk to themselves, their families, and their communities, as well as losses due to death from covid-19.

As I reflect on the pandemic's course I'm struck by two equal and opposing forces that have been in play. At one end is how resilient doctors have been-rapidly adapting to their new situations and rising to new challenges. At the other is their fragility. They too are human, with human vulnerabilities and the need to be cared for.

There is much talk about the NHS getting back to business as usual (or almost) and of doctors catching up on their paused work and reducing the backlog. But I have concerns. Already the support put in place at trust level is disappearing. Rest rooms are being re-commissioned. The daily meetings and team debriefings are being dismantled as people move back to their usual sites or have to be relocated to new ones.
We must not rush the process of getting back to business as usual and instead give doctors time to rest and recuperate. If we don't, I fear that many will not be in a good position to serve their patients, and more will need services such as mine.

Competing interests: See https://www.bmj.com/about-bmi/freelance-contributors. Commissioning and peer review: Commissioned; not externally peer reviewed.

This article is made freely available for use in accordance with BMJ's website terms and conditions for the duration of the covid-19 pandemic or until otherwise determined by BMJ. You may use, download and print the article for any lawful, non-commercial purpose (including text and data mining) provided that all copyright notices and trade marks are retained. 